\title{
A Study of the Model of Street Corner Space in the Central District of Chicago
}

\section{Shao Dian}

Urban Planning Department, College of Architecture, Southeast University, Nanjing, China

\section{Email address:}

1361830705@qq.com

\section{To cite this article:}

Shao Dian. A Study of the Model of Street Corner Space in the Central District of Chicago. Science Discovery. Vol. 5, No. 7, 2017 , pp. 545-553. doi: 10.11648/j.sd.20170507.23

Received: November 15, 2017; Accepted: November 23, 2017; Published: December 28, 2017

\begin{abstract}
Urban street corner space, as an indispensable part of urban public space, plays a positive and effective role in improving urban quality and vitality because of its extensive penetration and accessibility. In this paper, the central area of Chicago street corner space as the research object, through field investigation and theoretical analysis, summed up the characteristics and layout of Chicago street corner space characteristics. On the basis of summarizing four kinds of layout mode of the central area of Chicago street corner space, we conclude that they are building corner cutting type, bottom retreat type, leisure recreation type and landscape park type, and each model is discussed in detail. The final review and sort out the research Chinese corner space, combined with the Chicago street corner space mode, puts forward three suggestions on the construction of China corner space: space partition refinement and enhance the quality of the corner, implantation of multiple functions and activate the corner activity, integrating characteristic elements and show the style of the corner.
\end{abstract}

Keywords: Central District of Chicago, Street Corner Space Model, Chinese Street Corner Space

\section{芝加哥中心区街角空间模式研究}

邵典

建筑学院城市规划系, 中国南京东南大学, 南京, 中国

邮箱

1361830705@qq.com

摘要：城市街角空间作为城市公共空间不可或缺的部分, 因其广泛的渗透性和可达性对提升城市品质与活力具有积极 高效的作用。本文以芝加哥中心区街角空间为研究对象, 经过实地调研和理论分析, 总结出芝加哥街道布局特点以及 街角空间特色, 并以此为基础总结出芝加哥中心区街角空间的四种布局模式, 分别为建筑切角型、底层后退型、休闲 游憩型以及景观公园型, 并对每一种模式进行详细的探讨。最后对中国街角空间研究进行综述和梳理, 并结合芝加哥 街角空间模式, 对中国街角空间建设提出三点建议: 细化空间分区, 提升街角品质; 植入多元功能, 激活街角活力; 融入特色元素, 展现街角风貌。

关键词: 芝加哥中心区, 街角空间模式, 中国街角空间 


\section{1. 引言}

芝加哥是美国第三大城市，也是国际金融中心，它以 高楼大厦以及美丽的城市空间而著名。但是人们却忽视了 它同样美丽而具有特色的街角空间, 这是芝加哥街道活力 的凝聚。芝加哥街道的空间特点具有一定的典型性, 代表 了美国街角空间的建设方式。通过对芝加哥街角空间的研 究, 可以深入了解芝加哥街角空间构成的基本构成模式, 并以此为契机, 指导中国街角空间的建设。

中国的街角空间研究起步较晚, 在近二十年内之后才 逐步出现。戚毅君选取具有上海特色街角空间的研究和再 利用进行深入探讨，结合其所在的时间、空间提升其文化 特色和景观体验, 对城市中现状或已规划的城市空间提出 改造措施和建议[1]。朱小雷（2011）将广州西关社区的典 型公共街角空间作为研究对象, 综合利用问卷调查、观察 和访谈的方法对目标空间环境进行使用后评价（Post occupancy Evaluation, POE），并分析影响当地居民环境 取向和主观评价的内在因素, 剖析环境更新与居民生活空 间需求之间的关系, 总结环境更新的正反经验, 以期为进 一步的城市公共环境的整治积累第一手的反馈数据[2]。冷 凝从城市街角空间的概念出发, 阐述三亚城市街角空间的 功能特征和建设现状, 提出三亚城市街角空间建设的评价 标准, 并就如何进行节点型街边空间设计进行论述, 对三 亚城市街角空间建设研究具有示范与探索意义[3]。连泽峰 通过国外文献及数据调研分析,对比了不同国家城市街角 空间建设机制, 认为解决中国当前城市街角空间现状最迫 切的在于制定合理有效的建设机制, 最后结合现状提出对 中国的城市街角空间建设有可行性的机制[4]。总体而言, 中国目前已有的关于街角空间的研究数量较少, 研究的内 容也多集中于旧城改造等方面，在研究的角度、对象、问 题等方面存在一定的局限性。相比于中国, 多外的街角空 间研究相对较多, 但是多集中于建筑层面的研究, 且对中 国街角空间建设的借鉴意义较为不足。

相比于中国街角空间的建设, 芝加哥的街角空间建设 更具有在布局、结构、活力等方面的优势和特点, 并对中 国的街角空间建设具有一定的借鉴意义。因此本文将芝加 哥作为研究对象, 经过实地调研和数据采集, 在整理了芝 加哥街道布局特点、街角空间特色以及街角空间的利用情 况, 提出了芝加哥街角空间建设模式的几种类型的探讨。 并以此为基础, 对比中国的建设情况, 对中国未来的街角 空间建设提出几点建议和启示, 用以参考。

\section{2. 芝加哥中心区街角空间建设概况}

\section{1. 街道布局特点}

从城市总体路网形态来看, 芝加哥中心区路网呈现 “一环、四横、四纵”的地面路网骨架系（图1）。所有跨 越芝加哥河的干路均采用桥梁连接, 使路网具有非常好的 贯通性和可达性。位于芝加哥河东侧以及其支流南侧的几 条大街构成了中心区环线, 是外围交通进出中心区的主要 通道。为增加路网容量、分散交通矛盾、提供多通道选择, 规划建设了稠密的支路网系统, 交叉口最小间距仅 $60 \mathrm{~m}$,
最大也不超过 $150 \mathrm{~m}$, 并设置单向通行系统, 减少冲突点, 减化交通组织, 提高了路网整体运行效率。

而从街道布局来看, 芝加哥中心区呈现出“小街坊、 密路网、规则方格网状”的特点（图2）。20世纪90年代以 来, 美国城市规划界提出“新城市主义”的规划理念, 倡导 回归欧洲传统城镇空间形式，并结合“生态”、“低碳”的普 适价值观，进一步发展了以“密路网，小街区”为特征的城 市空间规划模式[9] [10]。申凤、李亮和翟辉从路网规划、 道路设计和静态交通三方面对这种密路网小街区的生成 进行了详细的阐述 [5]（图2）。

正是这种“小街坊、密路网、规则方格网状”的街道布 局, 为芝加哥街角空间的多样化营造提供了可能性, 为街 角空间的特色打造创造了基础条件。

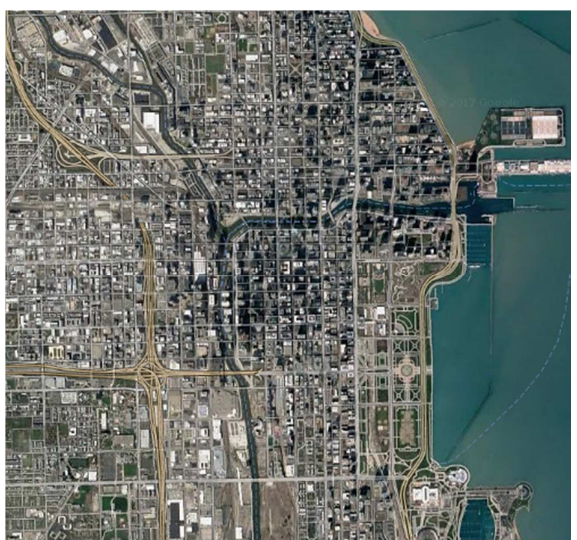

图1 芝加哥路网平面。
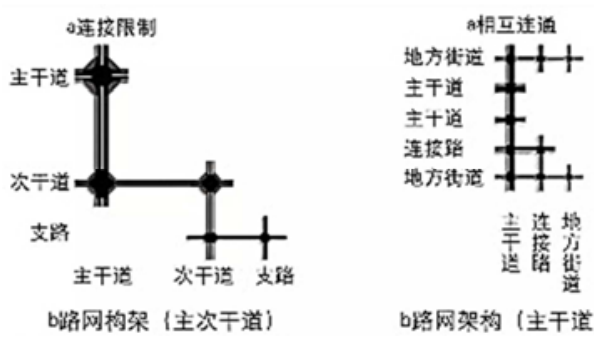

b路网架袍（主干道与连接垎）
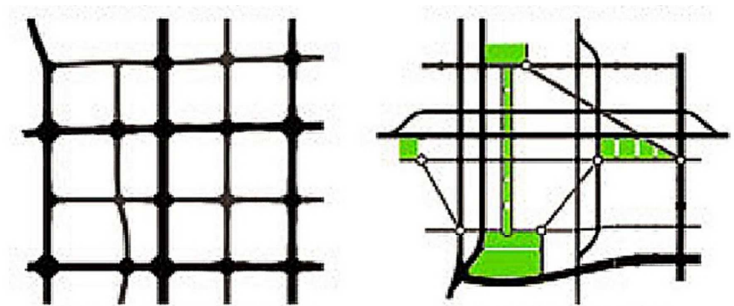

c加入树状支路及其他道路

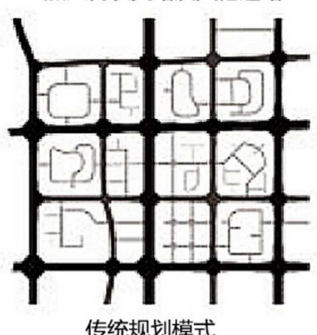

d加入网格状地方街道

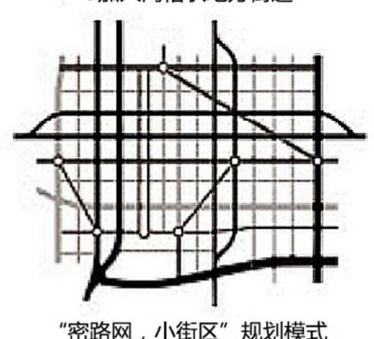

图2 “密路网, 小街区”模式的路网规划与道路设计。 


\section{2. 街角空间特色}

\subsection{1. 层次性}

街角空间的层次性主要体现在空间本体的层次性、景 观的层次性以及视觉的层次性。空间层次性表现在街角空 间的分层次处理, 利用空间的跌落、退台、连廊等, 使空 间立体化发展。景观的层次性集中在树种、花卉的选取以 及布置, 并结合颜色、种类的差异创造景观的前后层次感, 即所谓的“景深”。而视觉的层次性体现在视廊的变化以及 视觉体验的差异性。总体来说, 街角空间的层次性是街角 景观塑造的最主要方面。通过景观的塑造可以改变街角空 间原本景观单调的特点, 并美化城市空间。

\subsection{2. 多元性}

芝加哥街角空间不仅具有景观上的层次性, 在街角本 身的功能上也满足了多元性要求。与传统街角大多作为交 通步行空间不同, 芝加哥的街角空间融入了商业、休闲、 娱乐、游悡、绿地、交通等多种不同的元素，在通过不同 形式的边界去围合的同时又强调边界间的彼此渗透, 使街 角空间功能更为多元且形成一个协调的整体。这不仅满足 了不同人群的空间、功能上的体验要求, 又能使街角空间 得到充分利用, 并激发接到的活力。

\subsection{3. 特色性}

芝加哥街角空间另一个特质是其具有较强的特色性, 不同地段、不同功能的街角空间往往具备不同的风格, 包 括欧美传统风格、都市风格、宗教风格、当地风格等。而 这些风格的彰显依靠雕塑、雕文、铺地、设施、建筑立面、 店面招牌等元素来体现不同时代背景下的芝加哥特色。

\section{3. 芝加哥中心区街角空间模式探讨}

\section{1. 模式一：建筑切角型}

这是芝加哥街角类型中最为常见的一种类型, 由街角 的步行道和建筑角部两个部分构成, 是组成城市街角空间 肌理的“肉”, 也是展示街道形象的门户。总体来说包括建 筑直角、建筑斜切角、建筑圆切角以及街角特殊建筑四种 类型。

\section{1. 1. 建筑直角}

在多数城市中, 这是最为常见的一种街角空间模式, 这种空间有两部分构成——步行道以及建筑直角 (图3)。 相比于其他模式, 这一模式显得最为单调, 街角空间也很 难被利用。

而芝加哥的街角空间却显得美观大方。一种方法是采 用现代建筑与玻璃幕墙结合的方式, 内置商业功能, 从建 筑立面和整体形式上提升了街角空间品质（图4左）。另 一种是采用欧美传统风格建筑, 以暖灰色大理石和大开窗 的形式, 增加了立面的通透感, 使人站在街角却能看到内 部空间，强化了空间的渗透性（图4右）。
但是总体来说, 这一形式的街角空间相对缺乏活力, 也不能吸引来往的人群在此止步, 它往往充当的是展示城 市街道形象的角色。

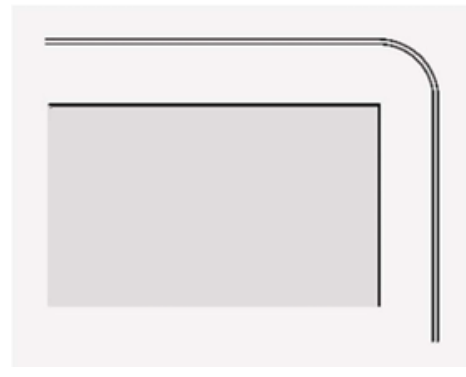

图3 建筑直角。

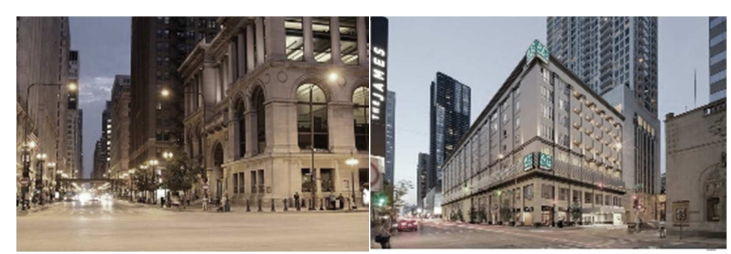

图4 建筑直角案例。

\section{1.2. 建筑斜切角}

建筑斜切角也是较为常见的一种街角形式, 建筑本身 往往是多层传统欧式建筑（图5）。在芝加哥哥特式传统 建筑较为常见, 通过修长的立柱、粗粘的大理石花岗岩以 及极具特色的长窗来构成街角空间（图6）。

与直角相比, 斜切角的街角空间更具亲和力和感染 力, 能使行人的视野相对更加开阔。同时, 斜角也弱化 了街道的十字交叉感, 使得同一街角的两个立面浑然一 体。在芝加哥, 这样的街角空间往往被用于地铁出口、 会议大楼出口、商业集会出入口等。

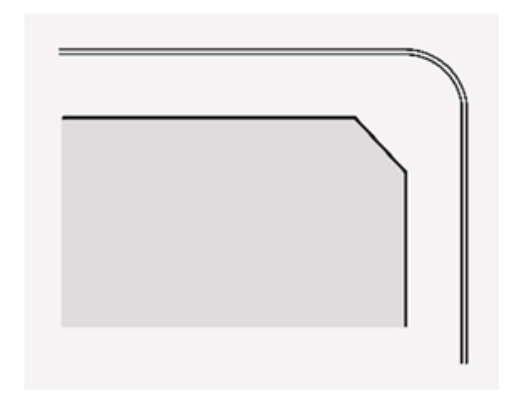

图5 建筑切斜角。

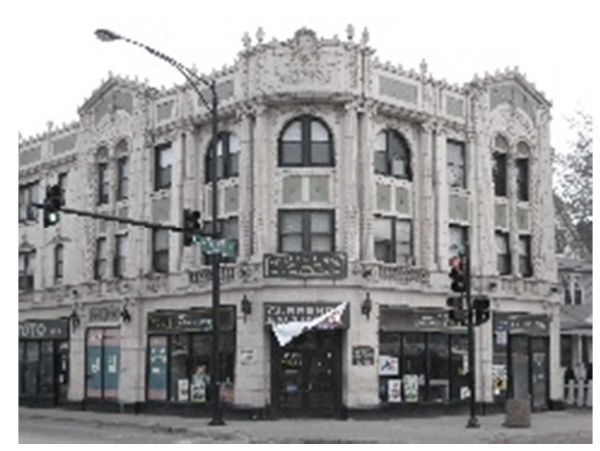

图6 建筑斜切角案例。 


\section{1. 3. 建筑圆切角}

在空间的体验性方面, 圆切角与斜切角具有异曲同工 之妙, 都能提高街道的开阔性以及提高街道立面的整体性 （图7）。

与斜切角不同的是, 圆形切角的底层往往与灰空间相 结合, 弱化了建筑“内外”的概念, 使人站在街角处, 既有 人在户外的感知, 又有仿佛来到建筑内部的错觉, 这一模 式强化和丰富了空间的层次感（图8）。

当然圆切角的街角空间也同在存在局限性。在芝加 哥, 这一形式的街角空间往往设施相对单一, 缺乏供人 驻足、游憩的活动空间, 活力性也相对不足。另一方面, 该类型街角空间在立面形式、铺地装饰、空间多样性等 方面的设计也略显贵乏。这导致了这种街角空间在被用 于提供行人通行的同时多被用于展示街道整体形象的功 能。

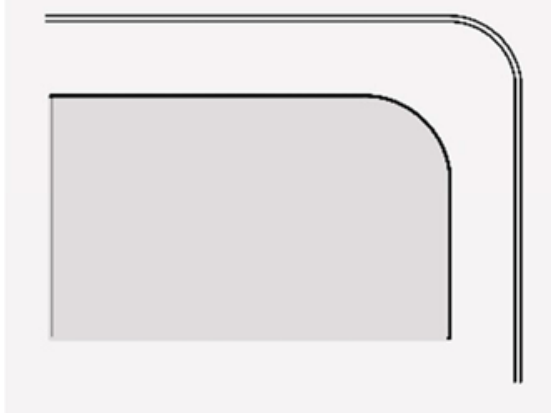

图7 建筑圆切角。

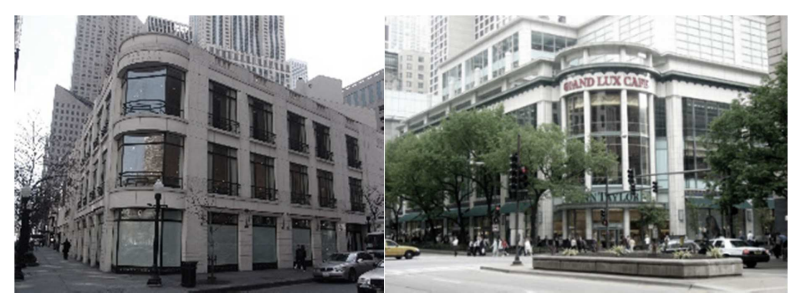

图8 建筑圆斜角案例。

\section{1. 4. 街角特殊建筑}

此处所指特殊建筑一般包括教堂、钟楼、历史建筑等 体量较小而具有特殊文化价值的建筑, 这类建筑由于体量 相对较小往往能够与街角空间相融合, 构成具有特殊文化、 历史或是时代内涵的街角空间（图9）。

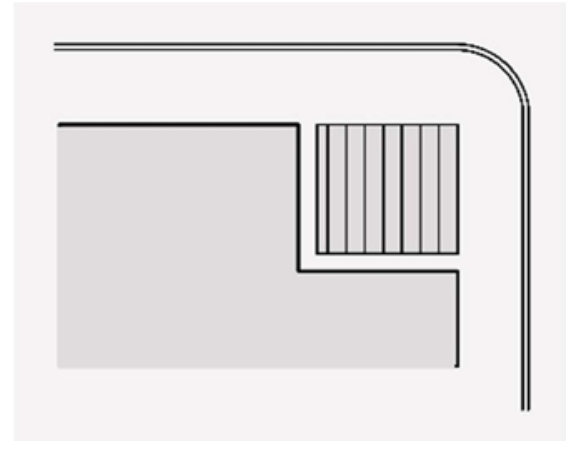

图9 街角特殊建筑。

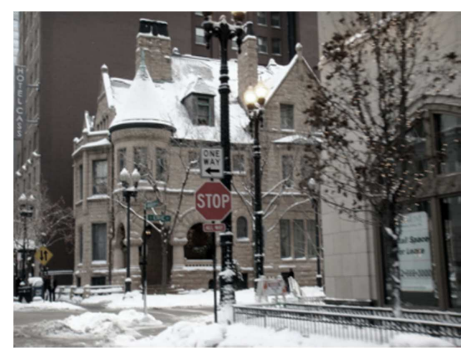

图10 街角特殊建筑案例。

这类街角空间往往具有较强的立体呈现感以及建筑形 式感, 可以作为片区范围内的标志性建筑或是标志性空间, 适合建筑特写或是事件定格的呈现。以芝加哥第四长老会 教堂为例, 这一教堂具有 100 多年的历史。在教堂与步行道 共筑成的街角空间中, 集聚着大量的人气和活力, 这些活 力不仅仅局限在教堂内部, 其外部空间配合休闲座椅、传 统风格路灯以及一个老旧的邮箱, 吸引了大量游客人群的 驻足和拍照。同时, 街角空间在诸多细节处也加以设计, 例如古朴的铺砖、快慢性分流线、这样雨棚、沿街绿地植 被的选择等, 满足了不同人群、不同时段的需求 (图10)。

这类街角空间做重在于体现其文化魅力与时代特点, 故需要建筑、铺地、设施、环境等方面共同营造。而芝加 哥第四长老会教堂内部更是收留了很多无家可归的黑人, 从这一细微方面更使人体会到基督教文化中关爱的一面, 赋予了街角空间更多的人文内涵。

\section{2. 模式二: 底层后退型}

底层后退型街角空间指街角建筑的底层（1-3层）采 用建筑后退的形式, 使街角获得更大的底层外部空间, 并 结合柱廊、玻璃幕墙、景观设施等, 创造空间层次更为丰 富、行为活动更加多样化的街角空间。芝加哥底层后退型 街角空间包含建筑角部后退、建筑一边后退以及建筑两边 后退三种类型。

\subsection{1. 建筑角部后退}

这是街角空间底层后退中最为常见的一种类型（图 11）。从建筑类型可以分为高层角部后退、多层角部后退 两类; 从建筑结构来看, 可以分为完全后退型以及局部后 退型，局部后退型往往采用立柱、承重墙等方式支撑后退 空间, 而其他墙体、幕墙等则向建筑内部退去, 形成一个 半开敞的灰空间。

高层角部后退式街角空间, 在世界各地都较为普遍, 而芝加哥的特殊之处在于其能够与街角空间相结合, 利用 退台、下沉、软硬结合等方式, 使建筑的后退空间不仅仅 只是供人出入大楼的交通空间，更是供人观赏、休息、阅 读、闲谈的公共休闲场所。这极大地提高了街角的空间活 力，最大限度发挥街角空间的利用效率（图12）。

而多层角部后退式街角空间则略有不同。在中国该类 型街角空间大多局限于城市公共建筑，例如图书馆、展览 馆、美术馆等, 但是由于其通常自成一体而与街道的结合 度较低, 导致了空间利用率极低。而芝加哥中心区则普遍 存在该类型街角空间, 并不局限于公共建筑, 普通的商业、 
办公甚至是酒店式公寓都会利用多层角部的后退, 来尽可 能地围合出更大、更有活力的街角空间。

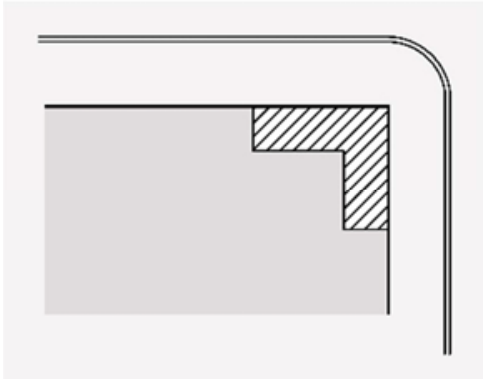

图11 建筑角部后退。

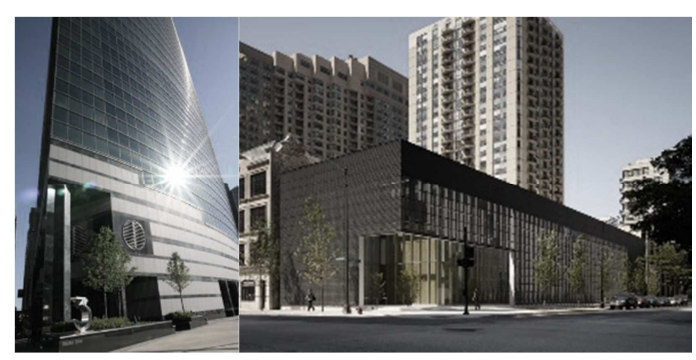

图12 建筑角部后退案例。

\subsection{2. 建筑一边后退}

建筑一边后退式街角空间是指建筑的某一条边通过完 全后退或是局部后退（通过用立柱、承重墙等）的方式与 街角步行道相结合开发形成的一种街角空间类型 (图13)。

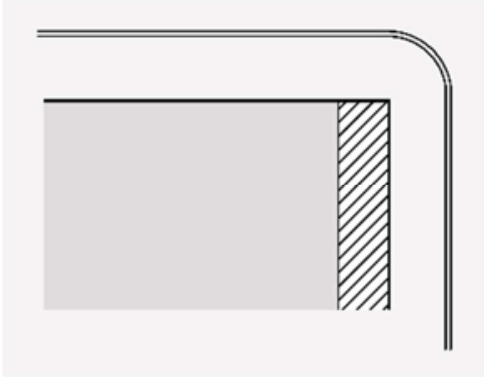

图13 建筑一边后退。

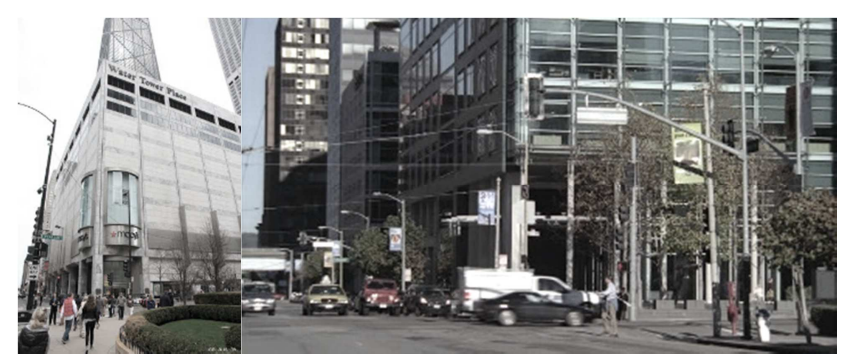

图14 建筑一边后退案例。

在芝加哥, 该空间与其他类型的底层后退街角空间不 同, 其往往承担着交通引导的功能, 常与地铁出口、休闲 广场、商业购物中心等公共职能较强的地段相连, 起到引 导人流的作用。因此, 人流量大、交通引导性强是其最明 显的特点。这也导致了相比于街角后退的形式，该类型街
角空间的层次性较为单一, 空间体验性较为薄弱。同时, 底层架空导致的半封闭特征吸引了大量的气正、流浪汉在 此落户, 成为了这一街角空间的一大特色（图14）。

\subsection{3. 建筑两边后退}

建筑两边后退式街角空间与一边后退式类似, 是建筑 的两边通过完全后退或是局部后退 (通过用立柱、承重墙 等) 的方式与街角步行道相结合开发形成的一种街角空间 类型（图15）。

然而与一边后退式相比, 两边后退式不再以交通人流的 引导为特征, 相反, 更加强调人流的集聚。这一类型的街角 空间的建筑以商业购物中心最为常见, 以 Century 21 Department为例, 通过建筑相邻两边建筑后退的形式, 拓宽 了步行道的宽度, 同时以建筑立柱为分界线, 实现了快慢行 分流，并为慢性购物游客提供了驻足观览的空间（图16）。

街角建筑的大面积后退, 也为街角空间的景观设计以 及设施建设提供了可能性。隔断式绿化带是最为常见的一 种景观类型, 常与之配套的还有公交站、吸烟室、座椅等 配套设施。这一开发模式对于中国购物商城的街角空间建 设具有一定的参考借鉴价值。

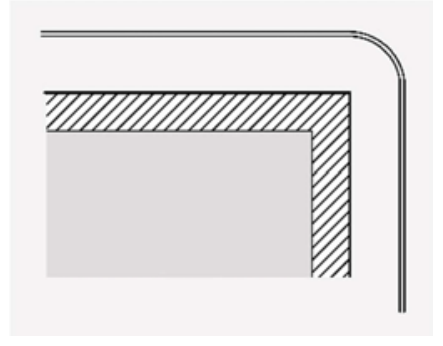

图 15 建筑两边后退。

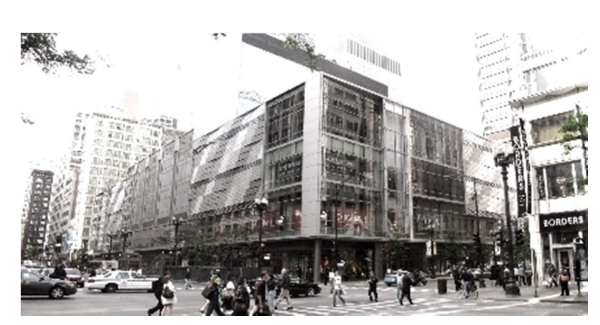

图 16 建筑两边后退案例。

\section{3. 模式三：休闲游稳型}

休闲游頽型街角空间是指以将休闲游咊设施置于街 角空间为特色的一种街角模式, 具体来说即将一定规模的 休闲座椅 (多配以商业功能) 或是游悡绿地置于街角的步 行空间, 从而形成的一种动静交融的街角空间。一般包含 街角休闲空间、路缘外休闲空间、路缘内休闲空间以及步 行道两侧休闲空间四种类型。

\section{3. 1. 街角休闲空间}

街角休闲空间是指休闲空间在道路交叉处且建筑角 部有一定后退的街角空间（图17）。这一类的街角空间大 致分为两种类型, 一种是以休闲广场为依托, 另一种以商 业功能为依托。 
以休闲广场为依托的街角休闲空间, 其空间设计主要 集中于广场铺地的设计、游线的划分、设施的分配以及树 木植被的选取。这一类型的街角空间可以集休闲、穿行为 一体, 在景观和功能上都能充分发挥街角空间的特色 (图 18左）。

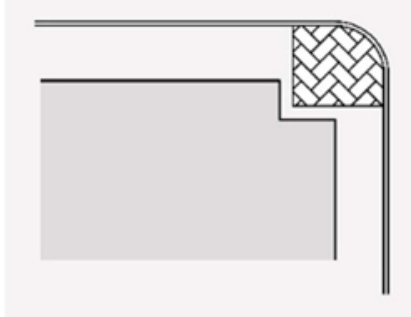

图17 街角休闲空间。

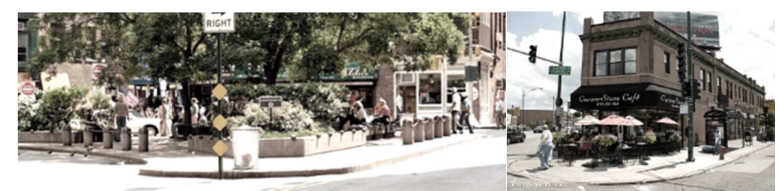

图18 街角休闲空间案例。

以商业功能为依托的街角休闲空间, 往往将休闲座椅 等与商业店面相结合, 是商业功能的户外拓展。相比于中 国的这一类街角空间, 芝加哥的更加宜人、美观，对街角 空间起到了加法作用。从空间的角度去剖析, 一个重要的 原因是在芝加哥多数这类型的街角空间, 用的都是具有传 统风格的浮雕围栏, 将步行道路和休闲座椅进行划分的同 时增加了街道的美感, 在繁忙的都市生活中增添了一份阴 凉和闲适（图18右）。

\section{3.2. 路缘外休闲空间}

此类街角空间较为特殊, 是通过将休闲空间外延的 形式来大道休闲与步行道结合的目的（图 19、20)。

伸出的空间一般长度在 1-2 米, 往往在其沿道路两 侧设置停车空间, 形成一条停车设施与景观休闲的结合 带。与传统的沿街停车位相比, 这一做法落实了“行人 友好”的原则, 改变人们传统思维中道路只能用于交通 的观念。

当然,这一类型的街角空间一般出现在交通量较小 的居住区, 以绿地景观和休闲设施为主要构成要素, 为 居民提供便利的户外娱乐场所。

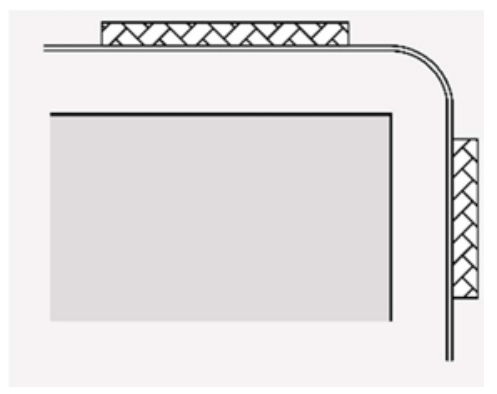

图19 路缘外休闲空间。

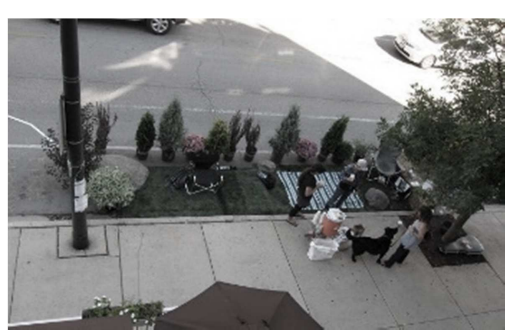

图20 路缘外休闲空间案例。

\section{3. 3. 路缘内休闲空间}

在空间结构上与路缘外休闲空间有着异曲同工之妙， 不同的是靠路缘内一侧的休闲空间更富于景观性（如图 21）。

在芝加哥, 这一类型的街道比比皆是, 尤其是集中 在滨水街道、城市轴线、公园临近街道等景观性较强的 地区, 往往在街道内缘布置有一定规模的花坛、绿地或 是景观休闲混合空间。相比于中国, 芝加哥的花坛景观 设计更具美感和艺术感，铁质的格棚将花簇包围，配合 乔木、路灯、座椅等能够打造出不同风格、不同特色的 街角空间（图22）。打造这一街角空间的核心是将景观、 建筑界面以及道路铺地三个达到一个微妙的视觉平衡, 这一平衡包括空间、颜色、材质等各个方面。

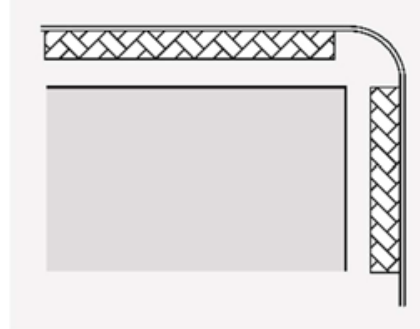

图21 路缘内休闲空间。

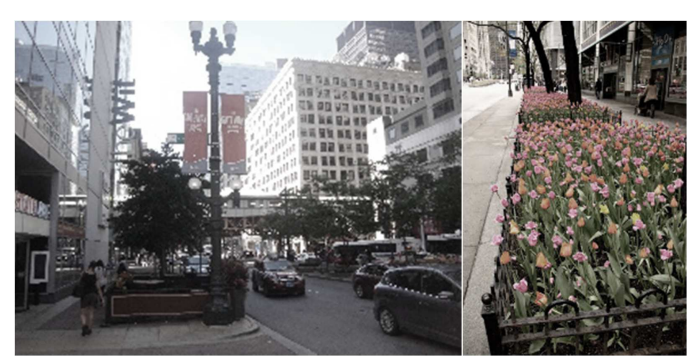

图22 路缘内休闲空间案例。

\section{3. 4. 步行道两侧休闲空间}

可以说, 步行到两侧休闲空间的街角模式是前三种休 闲空间模式的集合（图23）。在空间上，既有与建筑界面 紧贴的商业休闲座椅或是休闲绿地, 也有与步行道内缘一 侧紧邻的景观性休闲空间, 是芝加哥街角空间中商业、休 闲、景观彼此结合最紧密的一种模式。在这种街角空间, 交通穿行功能往往是最次要的, 而人的购物、停留、休闲 娱乐是这类街角空间最主要的功能属性（图24）。

在中国也有与之类似的街角空间, 但是往往被流动 摊贩、杂乱的商铺以及脏乱的街角卫生环境所取代。而 
芝加哥街角空间却显得整洁大方、尽然有序, 经过初步 的分析探讨, 总结出以下几个主要原因: 1. 良好的城市 管理, 在芝加哥大街小巷, 鲜有流通推贩的运营, 即便 有也是城市统一发放的流动贩卖车, 美观大方; 2 .边铺 管理有序, 室外的休闲商业座椅被栏杆围住, 不会占据 整个街角的位置, 更不会影响人流的穿行; 3. 整洁的街 道环境, 在芝加哥, 地上鲜有果皮纸屑等垃圾, 整洁的 底面是这一类型街道建设的关键。

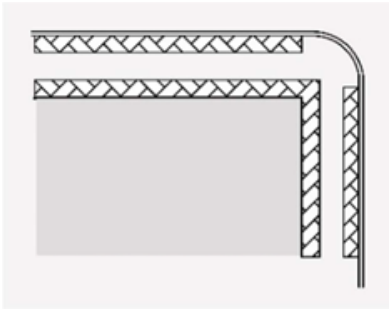

图23 步行到两侧休闲空间。

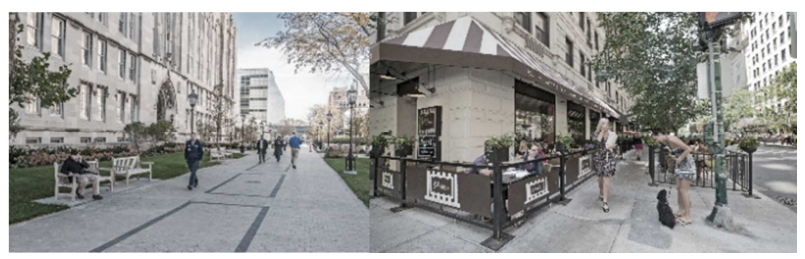

图24 步行到两侧休闲空间案例。

\section{4. 模式四：景观公园型}

景观绿地型街角空间与休闲游悡型不同，街角空间以 中型或大型绿地公园为主导, 更强调街角空间的景观性, 与绿地软质空间为主, 往往是城市片区的主要开放空间。 从规模的不同可以分为街角景观小品、街角公园、街角一 侧公园以及大型景观公园四种类型。

\section{4. 1. 街角景观标志}

这一类型以街角的某一景观性标志物为核心节点, 并与 绿地相结合共同构成具有标志性的街角空间景观（图）25。

这一类型的街角空间规模较小, 其重点在于标志物的 选取及其与绿地的结合。以芝加哥YOLK大楼前的街角空 间为例, 建筑采用角部后退的形式, 退界出的方形空间布 置花坛和绿地, 规模较小, 但是其中间设立的公司创始人 雕塑却立刻使得空间变得生动形象, 花坛中花卉的选择也 颇为考究, 选择不同色系、不同品种的花卉, 配以白色系 为主的建筑立面, 具有空间层次感和视觉冲击力 (图26)。

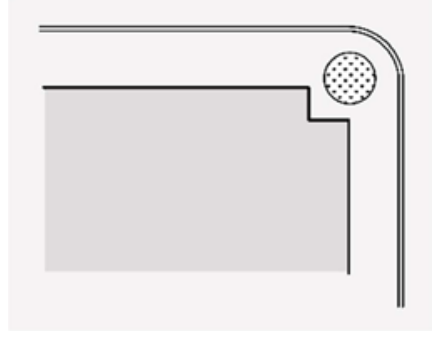

图25 街角景观标志。

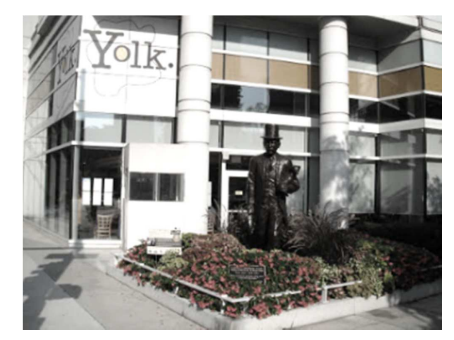

图26 街角景观标志案例。

\subsection{2. 街角公园}

街角公园空间与模式三中的街角休闲空间不同, 街角 休闲空间以硬地为主, 结合绿地植被为行人提供的是休闲 驻足购物的功能。而街角公园是在街角处设立面积较大的 绿地开放空间, 以绿化软地作为主要空间, 是城市片区级 别的生态中心（图27）。

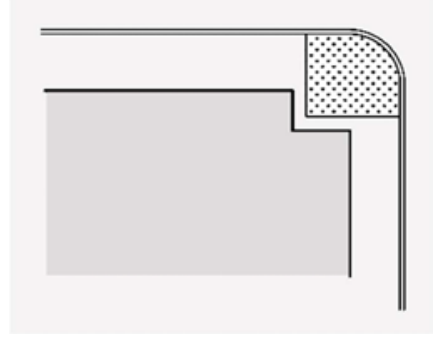

图27 街角公园。

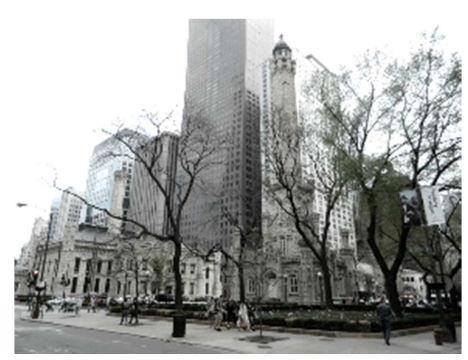

图28 街角公园案例。

这类街角公园是完全开放式的空间, 通常内部有硬质广 场、休秝桌椅甚至是篮球场等, 能够为周边市民提供服务。 与其他公园相比, 街角公园其特点在于更高的可达性以及城 市街道形象的美化性。在用地紧张的中国这类街角公园较为 少见, 而芝加哥则较为常见。正因为此, 街角公园不仅仅只 与商业、居住用地结合, 同时也常与商务办公、公共设施、 教堂等地块相结合, 为不同的人群提供便利（图28）。

\section{4. 3. 街角一侧公园}

街角一侧公园在建设的规模、功能上与街角公园类 似，但也存着差异性（图29）。

一方面是形态结构的差异。该类街角公园多为条带 状, 且内部游线铺地也多为线性空间, 具有一定的人行 导向性。另一个差异体现在公园的选址。街角公园没有 明确的选址要求, 而这类带状公园则多于重点建筑、地 铁出入口相结合布置, 其目的在于起到不同用地间连接 的作用, 通过游线的导向来引导行人（图30）。 


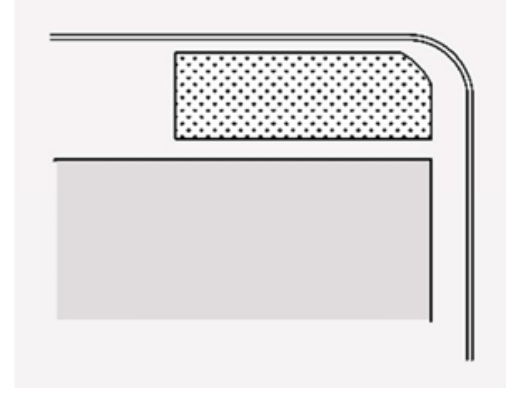

图29 街角一侧公园。

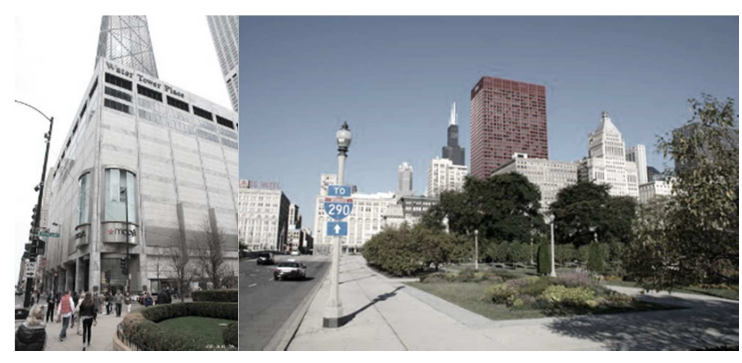

图30 街角一侧公园案例。

\subsection{4. 大型景观公园}

大型景观公园型街角空间是所有街角空间中规模最 大的一种, 以大型公园为核心空间, 建筑往往退居一侧, 是片区乃至城市的核心绿地空间。这一类的街角空间并不 仅局限于街角这样的中微观尺度, 而是从一个更为宏观的 尺度展现城市风貌（图31）。

与中国公园相比, 芝加哥的大型街角公园没有围栏等 设施，完全是向市民开放的公共空间。其功能不仅体现在 公园自身的服务内容, 更体现在街道或城市整体面貌的展 现（图32）。

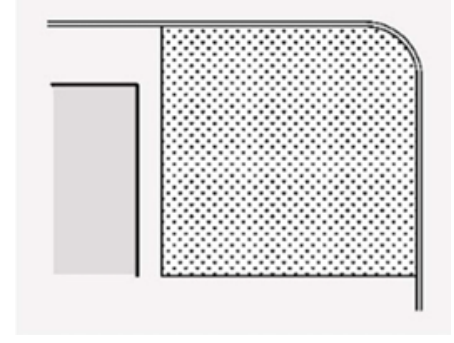

图 31 大型景观公园。

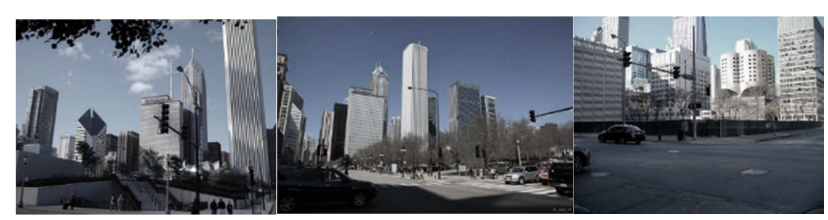

图 32 大型景观公园案例。

\section{4. 对中国街角空间建设的启示}

\section{1. 中国街角空间研究情况}

相比于国外, 中国对街角空间的研究相对较少, 理论 文献也较为不足, 缺乏完整的理论体系和技术路线。通过
对中国近几年来有关街角空间的研究进行了初步梳理, 大 致可以分为街角空间宏观理论研究、街角空间保护改造以 及街角空间建筑设计这三种类型。

街角空间宏观理论研究对街角空间最为系统全面的 一种研究方向, 可惜的是中国在这方面的研究成果少之又 少, 其中以连泽峰、杨建华的研究最具代表性[4]。该文献 对城市街角空间进行了概念的界定, 通过文献调查和现场 调查等方法来分析和阐述中国城市街角空间建设现状并 剖析其深层次原因, 并总结提出中国当前城市街角空间现 状最迫切的在于制定合理有效的建设机制, 最后结合国外 优秀案例提出中国街角空间建设的的方法和意见。

在中国有关街角空间保护改造方面的研究多集中在历 史街区的街角空间保护与改造, 研究多借助于案例的研究, 总结出相关改造建议和措施。例如朱小雷以经过一定程度 整治后的广州西关社区的典型公共街角空间为研究对象, 基于当地居民的日常生活视角, 综合利用问卷调查、观察 和访谈的方法对目标空间环境进行使用后评价, 剖析环境 更新与居民生活空间需求之间的关系，总结环境更新的正 反经验, 以期为进一步的城市公共环境的整治积累第一手 的反馈数据[2]; 戚毅君（2016）选取具有上海特色街角空 间的研究和再利用进行深入探讨, 使用手法相对简易、改 造动作相对较小、成效相对较快的城市改造手法, 将城市 中现状或已规划的城市空间进行改造和利用, 为以后的城 市更新、城市发展内容提供一些参考[1]; 李刚将保定历史 文化街区街角空间作为研究，从交通、休闲、景观等方面 深入研究街角空间, 在街角立面、雕塑、绘画、商铺等方 面提出改造建议来提升保定街角文化软实力 [6]。

中国还有一类关于街角空间的研究是侧重于建筑层 面的, 通过对建筑立面、材质、空间的设计来提升街角空 间品质。孙正以南京市中山北路与湖南路交叉口为例, 从 城市道路交叉口区域建筑形态的定义入手, 分析了交叉口 周围的建筑和由建筑所围合而成的空间, 提炼出其建筑所 具备的特点和空间所具有的性质, 并以中山北路与湖南路 交叉口为例。以期探索出适应中国发展的城市道路交叉口 区域的建筑形态[7]。黄乐颖从街角空间建设的诸多矛盾入 手, 以创造生态人性的生态办公建筑为切入点, 探讨了高 层建筑位于城市街角时空间处理的几种模式对城市环境 及景观的影响 [8]。

综上可以看出, 中国目前对于街角空间的研究仍停留 于理论探索阶段。一方面, 从宏观角度来研究城市街角空 间仅仅停留在机制研究方面, 缺乏更落地、更全面深入的 研究, 无法从空间上去分析街角空间建设的不足。另一方 面, 中微观尺度的研究则多“就事论事”, 总是从地方特色 出发寻求解决矛盾的突破口, 但这样很难跳出地方思维的 局限, 或许应该总更广的角度和思维来谋求更多的出路, 可以向西方优秀的街角空间学习借鉴, 扬长避短, 探索适 合中国街角空间建设的模式。

\section{2. 芝加哥模式的启示与中国街角空间建设的建议}

通过对芝加哥街角空间模式的探讨, 可以发现相比于 中国街角空间的建设, 芝加哥的街角建设理念显然更为先 进和超前。 
从空间角度对比研究可以发现芝加哥的街角空间更 具有层次性, 这层次性主要体现为空间的围合边界更加明 确, 同时边界与边界间又互相渗透。以休闲型街角空间为 例, 街角广场常采用跌落、退台的形式, 同时软硬地结合 布置，使空间的层次感更加分明，但是商业空间和步行空 间却往往通过围栏的形式形成明确的边界, 而这样的边界 却并非相互隔绝的, 而是通过绿地、功能业态相互渗透。 同时, 通过对比也可以发现芝加哥的街角空间更具有协调 性, 既能通过商业、广场、设施的结合使用来保证街角功 能的多样化, 又能够通过对立面、材质、绿化的统筹考虑 来达到街角景观的协调性。在有些重点地段, 更是通过欧 美传统元素的介入, 在街角空间既能体现都市风貌的同时 又不失传统韵味, 将街角空间真正打造成展现城市特色与 风貌的视觉空间。

基于此, 从空间角度入手提出中国街角空间建设的几 点意见, 来解决当前街角空间欠缺、单调、混乱的局面。

首先，细化空间分区，提升街角品质。将一个完整的 街角空间进行切割和划分, 可以结合退台、下沉、抬升等 方式，结合立体式交通将平面的空间改造为立体的三维空 间，一次提高空间的利用效率。同时实行软硬结合，根据 不同功能设计不同的流线, 配合以铺地的选择, 使得街角 空间更为丰富。

其次, 植入多元功能, 激活街角活力。根据街区自身 的功能定位将不同的功能植入街角空间, 例如商业店铺外 设置休闲座椅区、居住公寓街角设置休闲娱乐空间等，使 街角不再是单一的通行功能, 更能将人群活力吸引至街角 处, 活化街角空间。但是值得注意的是, 空间的管理和边 界的划定是植入功能的前提, 需要保证行人正常的通行以 及街角空间的整洁，否则极易导致街角的拥挤和脏乱。同 时, 根据情况的不同可以建设不同的休闲绿地或是景观绿 地, 包括街角公园、街边绿带等, 形式更加多元化, 在提 高了街角空间品质、激活了空间活力的同时也没话了街角 空间的整体面貌。

最后, 融入特色元素, 展现街角风貌。在学习芝加哥 街角空间的同时更不能抛弃城市原有的空间特色, 因此在 设计街角空间的同时需要维持或是融入城市自身特色。这 些特色元素不仅仅是街角的雕塑、小品, 更体现在街角设 施 (如座椅等) 与传统元素 (如传统印花、砖石铺地等) 的结合。只有这样才能重振街角空间风貌的同时烙上这个 城市特有的精神文化烙印。

\section{5. 结论}

城市街角空间是人们体验城市空间判断城市品质的 主要方式。而如何在中国现阶段宏观经济走弱、地方及国 家财政紧缩及的情况下, 转变街角空间受忽视的局面, 是 值得去研究和思考的问题。因此, 本文在基于芝加哥实地 调研的基础上, 从空间角度对芝加哥街角空间特点进行整 理和篎选, 整理出了一套芝加哥街角空间的建设模式。希 望借此能够汲取国外街角空间建设的优势和经验, 并结合 中国实情用之于中国街角空间的建设与改造

当然, 本文提出的芝加哥街角空间模式是基于调研和 理论分析的, 侧重于从空间角度去剖析芝加哥街角空间的 特点和优势, 缺少从宏观经济、政府管理、规划措施等角 度的深入分析, 同时也未经过实践过程的检验而缺少更多 实证性研究, 这将是今后研究重要做的重点工作。

\section{参考文献}

[1] 戚毅君. 浅谈上海街角空间改造利[J]. 智能城市, 2016

[2] 朱小雷. 旧城社区公共街角空间的使用后评价——以州 西关为例[J]. 华中建筑, 2011

[3] 冷凝. 三亚城市街角空间建设研究 [J]. 中国园艺文摘, 2017

[4] 连泽峰, 杨建华, 张甜甜. 寻找原动力一一城市街角空间建 设现状与机制研究[J]. 西部人居环境学刊, 2016

[5] 申风, 李亮, 翟辉. “密路网, 小街区”模式的路网规划与道 路设计一一以昆明呈贡新区核心区规划为例 [J]. 城市规划, 2016

[6] 李刚, 以街角打造保定历史文化空间, 提升保定文化软实 力[J]. 东方企业文化, 2014

[7] 孙正, 城市道路交叉口区域建筑形态分析一一南京市中 山北路与湖南路交叉口为例[J]. 江苏建筑, 2012

[8] 黄乐颖, 街角的矛盾——创造人性的生态办公建筑[J]. 福建 建筑, 2003

[9] 龚星星. 芝加哥中心区交通发展经验及启示 [J]. 城市交 通. 2009

[10] 陈雪明. 芝加哥城市交通系统简介[J]. 国际城市规划. 2013 